\title{
Real-time ultrasound elastography in 180 axillary lymph nodes: elasticity distribution in healthy lymph nodes and prediction of breast cancer metastases
}

Sebastian Wojcinski ${ }^{1 * \dagger}$, Jennifer Dupont ${ }^{2 \dagger}$, Werner Schmidt ${ }^{3}$, Michael Cassel ${ }^{4}$ and Peter Hillemanns ${ }^{1}$

\begin{abstract}
Background: To determine the general appearance of normal axillary lymph nodes (LNs) in real-time tissue sonoelastography and to explore the method/s potential value in the prediction of LN metastases.

Methods: Axillary LNs in healthy probands $(n=165)$ and metastatic LNs in breast cancer patients $(n=15)$ were examined with palpation, B-mode ultrasound, Doppler and sonoelastography (assessment of the elasticity of the cortex and the medulla). The elasticity distributions were compared and sensitivity (SE) and specificity (SP) were calculated. In an exploratory analysis, positive and negative predictive values (PPV, NPV) were calculated based upon the estimated prevalence of LN metastases in different risk groups.
\end{abstract}

Results: In the elastogram, the LN cortex was significantly harder than the medulla in both healthy $(p=0.004)$ and metastatic LNs $(p=0.005)$. Comparing healthy and metastatic $L N s$, there was no difference in the elasticity distribution of the medulla ( $p=0.281$ ), but we found a significantly harder cortex in metastatic LNs $(p=0.006)$. The SE of clinical examination, B-mode ultrasound, Doppler ultrasound and sonoelastography was revealed to be 13.3\%, $40.0 \%, 14.3 \%$ and $60.0 \%$, respectively, and SP was $88.4 \%, 96.8 \%, 95.6 \%$ and $79.6 \%$, respectively. The highest SE was achieved by the disjunctive combination of B-mode and elastographic features (cortex $>3 \mathrm{~mm}$ in B-mode or blue cortex in the elastogram, $\mathrm{SE}=73.3 \%$ ). The highest SP was achieved by the conjunctive combination of B-mode ultrasound and elastography (cortex $>3 \mathrm{~mm}$ in B-mode and blue cortex in the elastogram, SP=99.3\%).

Conclusions: Sonoelastography is a feasible method to visualize the elasticity distribution of LNs. Moreover, sonoelastography is capable of detecting elasticity differences between the cortex and medulla, and between metastatic and healthy LNs. Therefore, sonoelastography yields additional information about axillary LN status and can improve the PPV, although this method is still experimental.

Keywords: Breast ultrasound, Axillary lymph nodes, Sonoelastography, Real-time tissue elastography, Cancer detection, Elasticity imaging, HI-RTE, Lymph node metastases

\footnotetext{
*Correspondence: s@wojcinski.de

${ }^{\dagger}$ Equal contributors

'Hannover Medical School, Department for Obstetrics and Gynecology, OE

6410, Carl-Neuberg-Straße 1, Hannover 30625, Germany

Full list of author information is available at the end of the article
} 


\section{Background}

The prediction of axillary lymph node (LN) status remains an important issue in the preoperative assessment of breast cancer patients. Sentinel node biopsy (SNB) is the standard option for women that are staged with a negative nodal status [1-5]. Nevertheless, if axillary metastases are suspected, the success of SNB may be impaired. These patients should still receive axillary LN dissection (ALND) [6,7]. The procedure of radical ALND implies a significant increase in morbidity, such as lymphedema or paresthesia of the arm [8]. Provided that the preoperative assessment was correct, the precision of histological staging by SNB is very high and postoperative morbidity is significantly minimized [9]. Recently, omission of radical ALND in certain cases of positive sentinel nodes has been discussed [10,11].

However, the diagnostic precision of the preoperative assessment of the axillary LN status is far from perfect. Palpation of the axilla lacks sensitivity (SE) as only vast metastases are clinically apparent. Mammography does not fully cover the axillary region and the prediction of the malignant or benign character of LNs is not possible. On the other hand, B-mode ultrasound is known to be a precise method for the examination of the axilla with a SE of $45-73 \%$ and a specificity (SP) of $44-100 \%$, depending on the distinct B-mode criteria that are investigated $[12,13]$. Other imaging methods such as computer tomography (CT), magnetic resonance imaging (MRI), scintimammography and positron emission tomography (PET) have been investigated, but they have all demonstrated no relevant clinical advantage in the evaluation of the axilla. Additionally, they are overly expensive and labor-intensive [14-19].

Therefore, ultrasound remains the most suitable imaging method to assess axillary LNs, although the diagnostic accuracy is still unsatisfactory [20]. Technical advances like sonoelastography, tissue harmonic imaging and increasing frequencies may allow a better differentiation of benign and malignant masses [21-23]. Concerning the evaluation of breast lesions, sonoelastography has demonstrated an improved diagnostic performance when combining this method with B-mode ultrasound [22,24-26]. Sonoelastography has also been performed on cervical [27-29], mediastinal [30,31], celiac or mesenteric [32,33] and inguinal [34] LNs.

However, to the best of our knowledge, no data concerning sonoelastography of axillary LNs were published prior to the studies of Choi et al. $(n=64)$ and Taylor et al. $(n=50)$ in $2011[35,36]$. Therefore, our current results from 165 healthy and 15 metastatic LNs may expand the knowledge in this field of research to a certain degree.

Our primary study objective was to determine the typical color distributions of healthy LNs in the elastogram.
The secondary study objective was an exploratory analysis of the method/s potential value in the prediction of LN metastases when used as an adjunct to conventional B-mode ultrasound.

\section{Materials and methods}

Our study was carried out at the Breast Cancer Center in the University Hospital of Saarland, Homburg/Saar, Germany. The responsible ethics committee did not require additional approval for this non-interventional study design. The study cohort ( $n=180$ LNs) was recruited from patients who attended the outpatient service of our institution.

Healthy patients with no suspicious findings in the breast examination were eligible for the control group (group 1, $\mathrm{n}=165 \mathrm{LNs}$ ). In these patients, we performed the experimental sonoelastography of a randomly chosen axillary LN. Patients with a history of breast surgery concerning a larger resection volume, inflammatory conditions of the breast or systemic infections and skin disorders were excluded.

Patients with histologically-proven breast cancer before treatment were potentially eligible for group 2. In these patients, we performed experimental sonoelastography of an ipsilateral axillary LN. These breast cancer patients $(n=33)$ were scheduled to undergo surgery of the breast and the axilla. Concerning the previously studied LN, we used a skin marker for identification and correlated the pathological size with the ultrasonographic size in order to ensure that this was a representative specimen. Eighteen patients had benign axillary LNs on histological examination. These patients were excluded from analysis. The remaining fifteen patients showed metastases in the previously examined LN. These patients were assigned to the metastatic group (group 2, n=15 LNs).

\section{Ultrasound examinations and image analysis}

The routine examinations were performed by the author SW, a DEGUM (Deutsche Gesellschaft für Ultraschall in der Medizin, German society for ultrasound in medicine) level I certified senior physician in gynecology with four years experience in breast ultrasound [37]. The elastograms were obtained by the author JD, a doctoral fellow at our institution. All examinations were performed with the Hitachi EUB-8500 ultrasound system (Hitachi Medical Systems GmbH, Wiesbaden, Germany) using the Hitachi EUP-L54M probe $(50 \mathrm{~mm}, 6-13$ $\mathrm{MHz}$ ) and the integrated elastography module [38].

First, each LN was measured in two planes (i.e. three axes). Furthermore, we determined the dimension of the cortex and the medulla and performed color Doppler ultrasound. Pathological vascularization was defined as 
the presence of neoangiogenesis disrupting the capsule of the LN or an increased vascularization of the cortex. Next, experimental sonoelastography was carried out. The region of interest for the elastogram was chosen to encompass a maximum of $30 \%$ LN tissue and a minimum of $70 \%$ encircling tissue.

Image analysis was conducted by JD. As the analysis was performed before surgery, JD had no information about the final histological diagnosis in group 2. The B-mode and Doppler images of each LN were described by standard methods [39]. Concerning the elastogram, the elasticity distribution of the cortex and medulla were described as the predominant color of the particular anatomical region (red, yellow, green, turquoise or blue).

\section{Sonoelastography}

Dynamic real-time examinations using ultrasound to access the compressibility of breast lesions were introduced in the 1980s [40]. Today, numerous ultrasound manufacturers offer solutions that include elastography modules in the various ultrasound platforms. The principle of sonoelastography is that the tissue is subjected to a stress (i.e. compression) and the resulting strain (i.e. displacement) is assessed. Typically, the stress is applied by compressing the tissue with the ultrasound probe (freehand/handheld elastography). In addition, the newly developed method of shear wave elastography is under clinical evaluation [41]. This method utilizes an acoustic push pulse (vertically directed) to induce an elastic shear wave (horizontally directed) that propagates through the tissue. The velocity of the shear wave is measured by detection pulses and provides a semi-quantitative measurement of tissue stiffness [42]. In our study, we applied handheld sonoelastography
(Hitachi real-time tissue elastography, HI-RTE). This technology provides color elastograms, in which increasing tissue hardness appears as red, green and blue in ascending order on a continuous scale [Figures 1, 2, 3, 4, 5 and 6]. Therefore, the examiner receives information about the mechanical properties of the tissue.

\section{Statistical analysis}

Microsoft $^{\circledR}$ Office Excel ${ }^{\circledR} 2007$ (Microsoft Corporation) was used for data collection. The analysis was performed with MedCalc ${ }^{\circledR} 7.6$ statistical software (MedCalc Software bvba, Belgium). The Student's t-test was used for continuous data and comparison of means. Ultrasonographic features of benign and malignant LNs were compared using Fisher's exact test for univariate distributions. The predominant colors in the elastograms were compared using Yates' chi-square test for multivariate distributions of categorical data. When Yates' chi-square test was found to be significant, pairwise comparisons were performed using Fisher's exact test. For the calculation of 95\% confidence levels we used Newcombe intervals with continuity correction [43]. Specimen histology was the gold standard for the definition of metastatic LNs. Statistical significance was assumed at $\mathrm{p}<0.05$ for all tests.

\section{Results}

We analyzed 165 healthy LNs (group 1) and 15 metastatic LNs (group 2). The breast cancer patients (group 2) were significantly older $(58.3 \pm 7.4$ versus $50.2 \pm 12.9$ years, $\mathrm{p}=0.017)$, and had a significantly higher body mass index $\left(28.0 \pm 5.2\right.$ versus $\left.24.8 \pm 4.5 \mathrm{~kg} / \mathrm{m}^{2}, \mathrm{p}=0.012\right)$ than the healthy probands (group 1). There was no significant difference between the groups regarding the clinical presentation of the LNs (i.e. palpable mass $13.3 \%$ versus

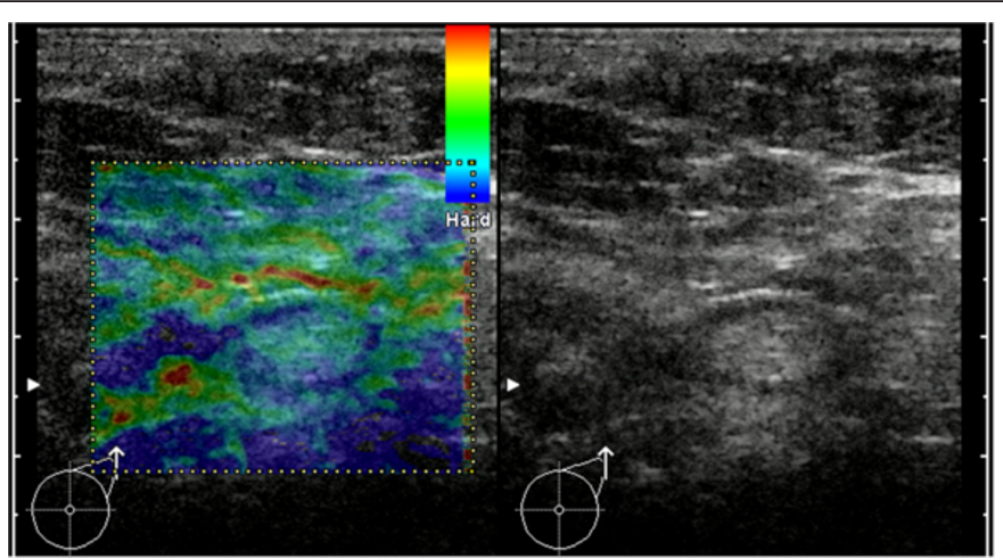

Figure 1 Example for B-mode ultrasound and elastogram of a healthy LN. In B-mode ultrasound the LN exhibits no criteria for malignancy. The predominant color of the medulla is green (with smaller areas of turquoise) and the cortex is mainly blue. Applying the criterion of a blue cortex, this case would be a false-positive. 


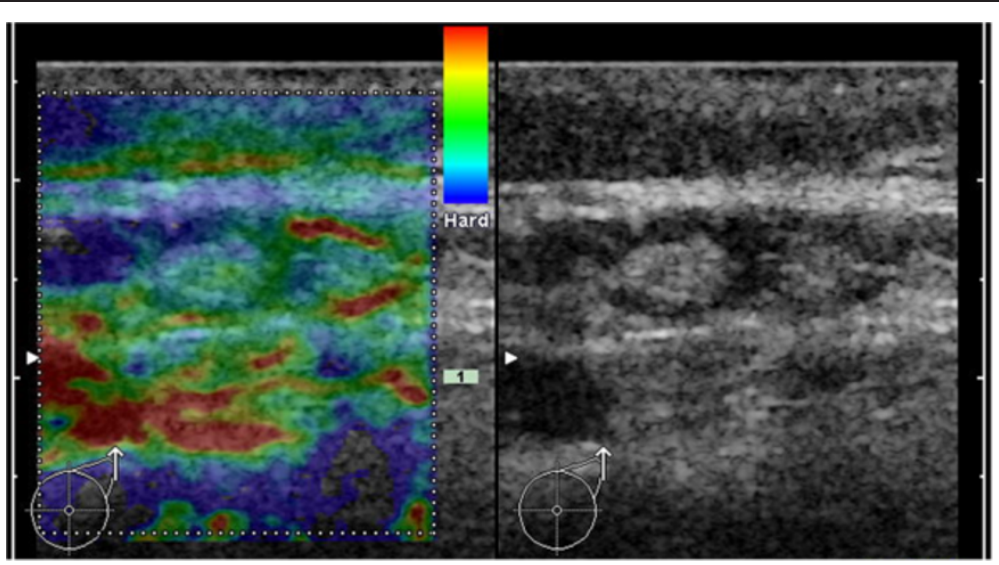

Figure 2 Example for B-mode ultrasound and elastogram of a healthy LN. In B-mode ultrasound the LN exhibits no criteria for malignancy. The predominant color of the medulla is turquoise (with smaller areas of green) and the cortex is mainly green. Applying the criterion of a blue cortex, this case would be a true-negative.

$11.6 \%, \mathrm{p}=0.690$, and painful palpation $0 \%$ versus $2.4 \%$, $\mathrm{p}=1.000)$.

\section{B-mode features and Doppler features of healthy and metastatic lymph nodes}

Regarding the horizontal size of the LNs and the diameter of the medulla, there were no significant differences between the groups. Nevertheless, the vertical dimension of metastatic LNs was significantly higher $(9.2 \mathrm{~mm}$ versus $7.2 \mathrm{~mm}, \mathrm{p}=0.013$ ). Focusing on the cortex, we found a significantly broader cortex for the metastatic LNs $(4.2 \mathrm{~mm}$ versus $1.4 \mathrm{~mm}, \mathrm{p}<0.001)$. Consequently, the cortex-to-medulla-ratio as well as the vertical-to-horizontalsize were significantly higher in the metastatic group $(\mathrm{p}<0.001$ and $\mathrm{p}=0.002$, respectively). A cortex greater than $3 \mathrm{~mm}$ was found in only $3.1 \%$ of the healthy LNs, compared to $40.0 \%$ of the metastatic LNs $(\mathrm{p}<0.001)$. The results are shown in Table 1.

\section{Elastograms of healthy and metastatic lymph nodes}

Focusing on the group of healthy LNs $(n=165)$, the predominant color of the cortex was yellow in $1.2 \%$, green in $13.9 \%$, turquoise in $64.2 \%$ and blue in $20.6 \%$ of the cases respectively, and never red [Table 2]. The medulla exhibited a similar distribution of the colors (3.0\%, 15.8\%, 73.9\% and $73.2 \%$, respectively, never red) [Table 3]. Nevertheless, the cortex and medulla color distributions were significantly different in the multivariate analysis $(\mathrm{p}=0.004)$, and the pairwise comparison revealed that the cortex was significantly more often described as blue (i.e. hard) than the medulla $(\mathrm{p}<0.001)$.

Focusing on the group of metastatic LNs $(n=15)$, the predominant color of the cortex was either turquoise $(40.0 \%)$ or blue $(60.0 \%)$ but never yellow, green or red [Table 2]. The medulla was yellow in $6.7 \%$, green in $33.3 \%$, turquoise in $53.3 \%$ and blue in $6.7 \%$ of cases, respectively [Table 3]. Accordingly, the difference between

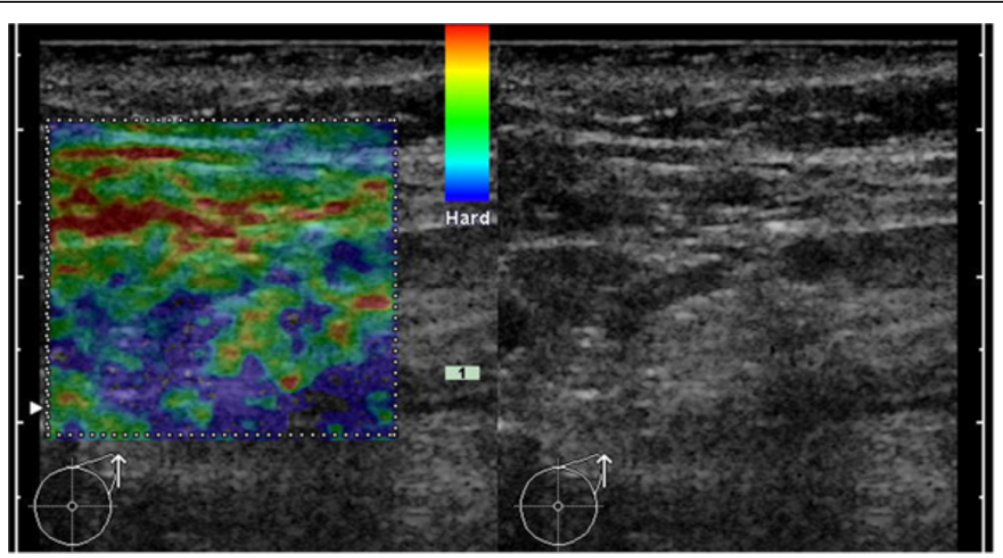

Figure 3 Example for B-mode ultrasound and elastogram of a healthy, reactive $L N$. In B-mode ultrasound the cortex of the $L N$ is slightly enlarge (maximum $\sim 2.5 \mathrm{~mm}$ ). The predominant color of the medulla is green (with smaller areas in other shades) and the cortex is mainly blue (with smaller areas of green). Applying the criterion of a blue cortex, this case would be a false-positive. 


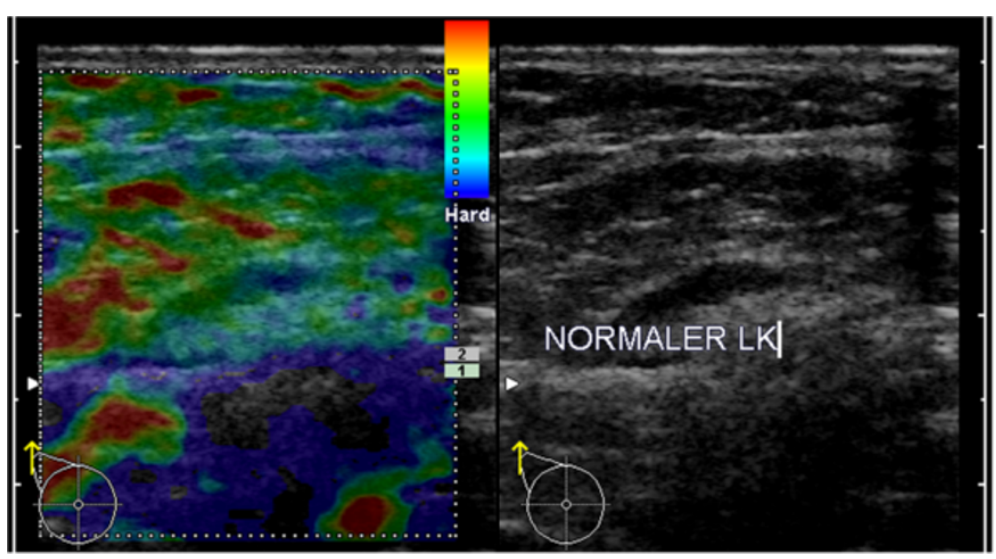

Figure 4 Example for B-mode ultrasound and elastogram of a healthy, reactive $\mathbf{L N}$. In B-mode ultrasound, the cortex of the LN is slightly enlarged (maximum $\sim 3.5 \mathrm{~mm}$ ). The predominant color of the medulla is turquoise (to green) and the cortex is mainly green. Applying the criterion of a blue cortex, this case would be a true-negative.

the cortex and the medulla was statistically significant in the multivariate analysis $(\mathrm{p}=0.005)$.

Comparing the two groups, there was no difference regarding the color distribution of the medulla [Table 3]. However, we found a significant difference regarding the color distribution of the cortex $(\mathrm{p}=0.005)$. Compared to healthy LNs, the cortex of metastatic LNs was significantly more often blue $(60.0 \%$ versus $20.6 \%, \mathrm{p}=0.005)$ [Table 2].

Sensitivity and specificity of B-mode ultrasound, Doppler ultrasound, sonoelastography and clinical examination Analyzing the performance of single criteria, a cortex broader than $3 \mathrm{~mm}$ in B-mode ultrasound yielded an excellent specificity (96.8\%) and a low sensitivity (40.0\%). Concerning sonoelastography, we applied the criterion of a blue cortex and achieved a well-balanced specificity of $79.6 \%$ and a sensitivity of $60.0 \%$.
In order to explore the combinations of different ultrasound criteria, we combined the B-mode feature "cortex broader than $3 \mathrm{~mm}$ " and the elastographic feature "blue cortex". In the disjunctive combination (LNs that fulfill at least one criterion were regarded as positive), the specificity was $77.5 \%$ and the sensitivity was higher than with any other criterion, namely $73.3 \%$. In the conjunctive combination (only LNs that fulfill both criteria were regarded as positive), the specificity reached an excellent level of 99.3\% (higher than with any other criterion) and the sensitivity was $26.7 \%$ [Table 4 ].

Model calculation concerning the diagnostic performance of B-mode ultrasound and sonoelastography

Calculation of the negative and positive predictive values (NPV, PPV) should be based on the particular prevalence in the observed collective. The prevalence of LN metastases in individual subgroups is dependent on the

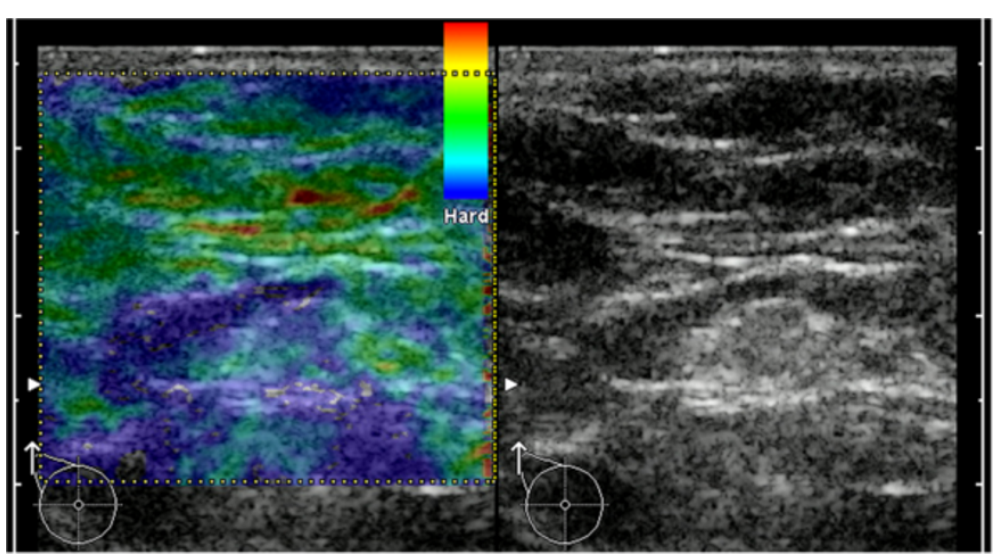

Figure 5 Example for B-mode ultrasound and elastogram of a metastatic LN. In B-mode ultrasound, the cortex of the LN is slightly enlarged (maximum $\sim 3.5 \mathrm{~mm}$ ). The predominant color of the medulla is turquoise (to green) and the cortex is mainly blue. Applying the criterion of a blue cortex, this case would be a true-positive. 


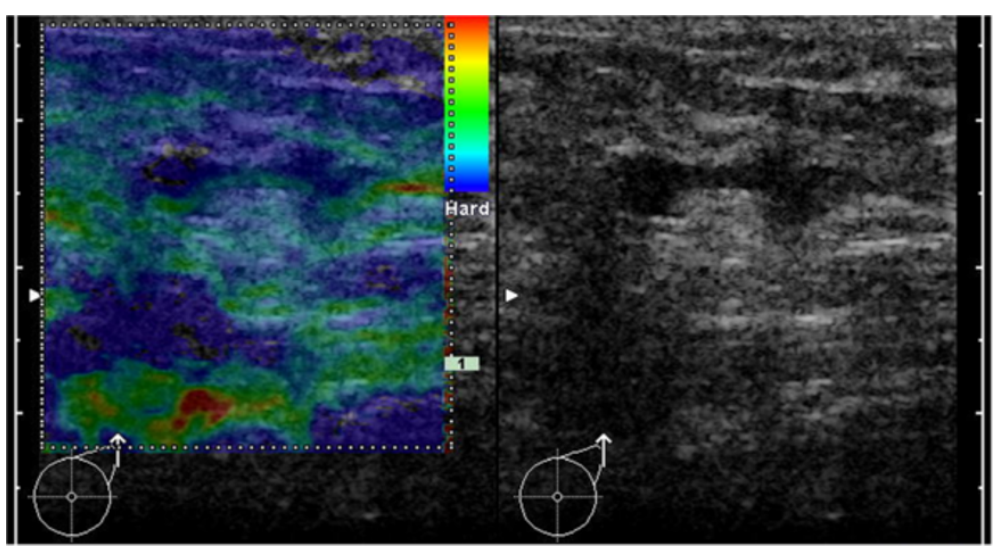

Figure 6 Example for B-mode ultrasound and elastogram of a metastatic LN. In B-mode ultrasound, the cortex of the LN is slightly enlarged (maximum $\sim 3.0 \mathrm{~mm}$ ). The predominant color of the medulla is turquoise and cortex is mainly blue. Applying the criterion of a blue cortex, this case would be a true-positive.

tumor stage, among other factors [44-46]. In mixed collectives, the prevalence of LN metastases is estimated to be about $45 \%$ [47], which is concordant with our collective (45.5\%). In particular, tumors categorized as T1 show LN metastases in about $25.9 \%$ of cases, whereas in T2 tumors, LN metastases occur in about 48.2\% [48]. Based on the prevalence of LN involvement within these two risk groups, the following predictive values result:

In T1 tumors (with an estimated prevalence of LN metastases of 25.9\%), the best B-mode criterion (cortex $>3 \mathrm{~mm}$ ) can be expected to yield a PPV of about $81 \%$ and an NPV of $\sim 82 \%$. The conjunctive combination with the best elastographic criterion (blue cortex) leads to an improved PPV of $\sim 93 \%$ with little effect on the NPV $(\sim 79 \%)$.

In T2 tumors (with an estimated prevalence of LN metastases of 48.2\%), B-mode ultrasound can be expected to have a PPV of $\sim 92 \%$ and a NPV of $\sim 63 \%$. The conjunctive combination with sonoelastography improves the PPV ( 97\%), but also impairs the NPV ( 59\%).

\section{Discussion}

Sonoelastography only offers a relative measurement of tissue stiffness and is dependent on the surrounding tissue [49]. We propose a relatively simple criterion (i.e. blue cortex) as the most suitable predictor of malignancy in LNs. The fact that the cortex of metastatic LNs is significantly harder than the cortex of healthy LNs is reflected in the predominance of the colors blue and turquoise in the elastograms. Applying this single criterion, the examination with sonoelastography resulted in an SE of $60.0 \%$ and an SP of $79.6 \%$.

However, the combination of various criteria from several imaging methods is known to improve the performance. This principle is also used in breast diagnostics,

Table 1 B-mode features and Doppler sonography of healthy and metastatic LNs (mean \pm standard deviation, n.s. = not significant, $L N=$ lymph node)

\begin{tabular}{lccc}
\hline LN characteristics & Group $\mathbf{1}$ healthy LNs & Group 2 metastatic LNs & p \\
\hline $\mathbf{n}$ & 165 & 15 & n.s. $(0.126)$ \\
Distance from the skin $(\mathbf{m m})$ & $13.5 \pm 5.1$ & $15.5 \pm 3.0$ & n.s. $(0.406)$ \\
Horizontal size $(\mathbf{m m})$ & $15.8 \pm 6.4$ & $9.4 \pm 7.0$ & 0.013 \\
Vertical size $(\mathbf{m m})$ & $7.2 \pm 3.0$ & $0.70 \pm 0.26$ & 0.002 \\
Vertical-to-horizontal-size (ratio) & $0.50 \pm 0.24$ & $4.2 \pm 4.7$ & $<0.001$ \\
Cortex $(\mathbf{m m})$ & $1.4 \pm 0.7$ & $4.1 \pm 2.1$ & n.s. $(0.299)$ \\
Medulla $(\mathbf{m m})$ & $4.8 \pm 2.4$ & $1.22 \pm 1.75$ & $<0.001$ \\
Cortex-to-medulla (ratio) & $0.39 \pm 0.31$ & $40.0 \%$ & $<0.001$ \\
Cortex $>$ 3mm & $3.1 \%$ & $40.0 \%$ & $<0.001$ \\
Architectural distortions & $0.6 \%$ & $14.3 \%$ & n.s. $(0.109)$ \\
Pathologic vascularization & $4.4 \%$ & &
\end{tabular}


Table 2 Predominant color of the cortex in sonoelastography with respect to healthy and metastatic LNs

\begin{tabular}{lccc}
\hline Cortex & Group $\mathbf{1}$ healthy LNs $\mathbf{n = 1 6 5}$ & Group $\mathbf{2}$ metastatic LNs $\mathbf{n = 1 5}$ & $\mathbf{p}$ (pairwise comparison) \\
\hline red (soft) & $0 \%$ & $0 \%$ & n.a. \\
yellow & $1.2 \%$ & $0 \%$ & n.s. (1.000) \\
green & $13.9 \%$ & $0 \%$ & n.s. (0.223) \\
turquoise & $64.2 \%$ & $40.0 \%$ & n.s. (0.093) \\
blue (hard) & $20.6 \%$ & $60.0 \%$ & 0.001 \\
p-value (multivariate analysis) & & & \\
\hline
\end{tabular}

The cortex of metastatic LNs is significantly harder and therefore significantly more often described as blue than the cortex of healthy LNs. (n.s. = not significant, n.a. $=$ not applicable, $\mathrm{LN}=$ lymph node).

when different ultrasound features of a lesion are combined, or mammography and MRI are added [50]. Consequently, we combined our best B-mode criterion and the most plausible elastographic criterion in order to investigate the effect on SE and SP. The conjunctive combination of B-mode and sonoelastography resulted in an improved performance. Due to the high specificity of the method, the PPV increased, while the effect on the NPV was only marginal and without clinical relevance.

However, a false negative preoperative evaluation usually results in the resection of a metastatic involved sentinel node. This scenario implies no relevant risk to the patient. On the other hand, a false positive evaluation of axillary LN status may result in an unnecessary axillary dissection instead of sentinel node biopsy with a potentially increased morbidity. Therefore, a beneficial effect of the complementary use of sonoelastography is very likely. We propose that these aspects should be investigated further.

\section{Literature overview}

Concerning breast masses, a scoring system (the socalled Tsukuba Elasticity Score, Itoh Score or Elasticity Score) is commonly used, which refers to the distribution of different colors within a lesion [51]. Obviously, this scoring system was developed for breast lesions and is not applicable to LNs.

For the elastographic assessment of cervical LNs, Lyshchik et al. determined an individual four-point rating scale including the visibility, relative brightness, margin regularity, and margin definition of the LNs in the elastogram. In the evaluation of 141 patients, they described an SP of $98 \%$, an SE of $85 \%$ and an accuracy of 92\% [27].

Saftiou et al. reported on cervical, mediastinal and abdominal LNs examined with endoscopic ultrasound elastography. The evaluation of the pictures was performed using a pattern analysis with RGB channel histograms. In their collective study of $42 \mathrm{LNs}$, they achieved an SP of $94.4 \%$ and an SE of $91.7 \%$ [52].

Taylor et al. performed sonoelastography in 50 breast cancer patients. They evaluated the LNs in the elastogram with either an individual visual scoring system or an individual strain scoring system. The authors described an SE and SP of 76\% and 78\% for conventional ultrasound, $90 \%$ and $86 \%$ for visual scoring, and $100 \%$ and $48 \%$ for strain scoring, respectively [36].

Alam et al. published data on cervical LNs in 85 patients. The authors analyzed the distribution and percentage of the LN area with high elasticity (i.e. hard, blue), with pattern 1 being an absent or very small hard area and pattern 5 indicating a hard area occupying the entire LN. The cutoff line for reactive versus metastatic was set between patterns 2 and 3. The authors reported an SE of $83 \%$ and an SP of $100 \%$ [28].

Choi et al. modified this system and classified 64 axillary LNs using a 4-point color scale based on the percentage and distribution of the $\mathrm{LN}$ areas with high elasticity (i.e. hard, blue). They achieved an SE of 80.7\% and an SP of 66.7\% [35]. These results do not fully comply with the previously described studies and our own

Table 3 Predominant color of the medulla in sonoelastography with respect to healthy and metastatic LNs

\begin{tabular}{lccc}
\hline Medulla & Group $\mathbf{1}$ Healthy $\mathbf{L N} \mathbf{n}=\mathbf{1 6 5}$ & Group 2 Metastatic LNs $\mathbf{n = 1 5}$ & $\mathbf{p}$ (pairwise comparison) \\
\hline red (soft) & $0 \%$ & $0 \%$ & n.a. \\
yellow & $3.0 \%$ & $6.7 \%$ & n.a. \\
green & $15.8 \%$ & $33.3 \%$ & n.a. \\
turquoise & $73.9 \%$ & $53.3 \%$ & n.a. \\
blue (hard) & $7.3 \%$ & $6.7 \%$ & n.a. \\
p-value (multivariate analysis) & & n.s. $(0.281)$ & \\
\hline
\end{tabular}

There is no difference between the two groups. (n.s. = not significant, n.a. = not applicable as the multivariate analysis was negative, $\mathrm{LN}=\mathrm{lymph}$ node). 


\begin{tabular}{|c|c|c|}
\hline Prediction of LN status & Sensitivity & Specificity \\
\hline \multirow[t]{2}{*}{ B-Mode-US: Cortex $>3 \mathrm{~mm}$} & 40.0 & 96.8 \\
\hline & $(17.5-67.1)$ & $(92.5-98.8)$ \\
\hline \multirow[t]{2}{*}{ Doppler-US: Pathologic vessels } & 14.3 & 95.6 \\
\hline & $(2.5-43.9)$ & $(90.8-98.1)$ \\
\hline \multirow[t]{2}{*}{ Clinical examination: Palpable LNs } & 13.3 & 88.4 \\
\hline & $(2.3-41.6)$ & $(82.3-92.7)$ \\
\hline \multirow[t]{2}{*}{ Elastogram: Cortex "blue" } & 60.0 & 79.6 \\
\hline & $(32.9-82.5)$ & $(72.2-85.5)$ \\
\hline \multirow{2}{*}{$\begin{array}{l}\text { Disjunctive combination: } \\
\text { Cortex }>3 \mathrm{~mm} \text { or "blue" in } \\
\text { the elastogram }\end{array}$} & 73.3 & 77.5 \\
\hline & $(44.8-91.1)$ & $(69.8-83.7)$ \\
\hline \multirow{2}{*}{$\begin{array}{l}\text { Conjunctive combination: } \\
\text { Cortex }>3 \mathrm{~mm} \text { and "blue" } \\
\text { in the elastogram }\end{array}$} & 26.7 & 99.3 \\
\hline & $(8.9-55.2)$ & $(95.8-100.0$ \\
\hline
\end{tabular}

results, as a high SP and a moderate SE is usually observed in elastography.

Generally, the performance of sonoelastography is remarkably good in studies from the literature. Nevertheless, we have to consider that these data are from dissimilar, small patient collectives, the LNs are examined in different regions of the body, and the methods show relevant variations. Therefore, more advanced comparisons of the data are not possible.

Despite these reports, we have chosen a different approach for the evaluation of the elastograms, as we propagate the idea that the cortex and the medulla of an LN should be evaluated separately. Furthermore, we tried to avoid cumbersome scoring systems. For the evaluation of the elastograms we used a simple 5-point color scale describing the predominant color of the distinct structure (red, yellow, green, turquoise, or blue) as it appears in the elastogram.

Our approach is concordant with the preliminary results of Giovannini et al., who investigated LNs with endoscopic sonoelastography in 49 patients. The authors described a high SE (100\%) and a moderate SP (50\%) for sonoelastography using the criterion of a homogeneously blue cortex [33].

Metastases develop preferentially in the LN cortex and cause tissue alterations. As demonstrated by our results, sonoelastography seems to be capable of detecting these minute changes in elasticity distribution, although the LN cortex only constitutes a tissue structure of a few millimeters in size.

Another option for the interpretation of elastograms is the calculation of the strain-ratio [24,25]. This mode has not been systematically analyzed in LNs and could be a matter for future research.

\section{Limitations of our study}

The main limitation of our study is that we have no validated criteria for the description of LNs in the elastogram. Accordingly, the analysis of the predominant color is, to a certain degree, observer-dependent, as it is based on image interpretation. Nevertheless, the evaluation of B-mode images is also observer-dependent and a matter of subjective interpretation. To minimize this limitation, we chose a simplified evaluation algorithm based on five categories (predominant color described as red, yellow, green, turquoise, or blue). The analysis of inter-observer concordance could be a matter for future research.

Furthermore, the still image of the elastogram is randomly depicted by the examiner during the real-time examination. This implies the risk of an observation bias. Nevertheless, this is unavoidable and has proven stable results in previous elastographic studies of LNs [52].

Finally, the analysis of SP, PPV and NPV is limited by the fact, that a group of healthy women is probably not the optimal choice for the control group, as lymph node morphology may differ even between healthy women and node negative breast cancer patients. Furthermore, there are vast confidence intervals around parameter estimated due to the small sample size. Further studies with larger collectives consisting exclusively of breast cancer patients may yield more accurate results.

\section{Conclusion}

- The cortex of healthy LNs is typically harder (i.e. has a higher elasticity) than the medulla.

- The cortex of malignant LNs is typically harder (i.e. has a higher elasticity) than the medulla.

- Comparing healthy LNs and metastatic LNs, the cortex of metastatic LNs is significantly harder (i.e. has a higher elasticity) than the cortex of healthy LNs.

- The definition of a blue cortex in the elastogram as a criterion for malignancy is feasible.

- Concerning the prediction of LN status, the combination of B-mode ultrasound with sonoelastography may be superior to B-mode ultrasound alone.

- The best specificity (99.3\%) may be achieved by conjunctively combining B-mode ultrasound with the elastogram (cortex $>3 \mathrm{~mm}$ and cortex blue), although the sensitivity is low in this setting (26.7\%).

- The conjunctive combinations of B-mode ultrasound and sonoelastography may improve the PPV (i.e. reduced false positive rate), but there may 
be an impairment of the NPV (i.e. increased false negative rate).

- Sonoelastography of axillary LNs must still be regarded as an experimental method. Nevertheless, in the hands of an experienced sonographer, the method of real-time sonoelastography may provide useful information about axillary LNs even today.

\section{Abbreviations}

ALND: Axillary lymph node dissection; CT: Computer tomography; LN: Lymph node; MRI: Magnetic resonance imaging; n.a.: not applicable; n.s.: not significant; NPV: Negative predictive value; PET: Positron emission tomography; PPV: Positive predictive value; SE: Sensitivity; SNB: Sentinel node biopsy; SP: Specificity.

\section{Competing interests}

The author's declare that they have no competing interests.

\section{Authors' contributions}

SW contributed to the conception and design of the study and WS provided methodological advice. JD performed the ultrasound examinations and data collection. SW and JD contributed to the analysis and interpretation of the data and the writing of the manuscript. MC contributed to the writing and the reviewing of the manuscript. FD, $\mathrm{PH}$ and $\mathrm{SW}$ conducted the final review of the data and the manuscript. SW, JD, WS and MC were employees at the University Hospital of Saarland at the time of the study. All authors read and approved the final manuscript.

\section{Acknowledgements}

Publication costs were covered by a grant of the DFG (German Research Foundation) within the project "Open Access Publications" at MHH (Hannover Medical School, Germany).

\section{Author details}

${ }^{1}$ Hannover Medical School, Department for Obstetrics and Gynecology, OE 6410, Carl-Neuberg-Straße 1, Hannover 30625, Germany. ${ }^{2}$ Main-Taunus-Kreis Hospital, Department for Obstetrics and Gynecology, Bad Soden, Germany. ${ }^{3}$ University Hospital of Saarland, Department for Obstetrics and Gynecology, Homburg/Saar, Germany. "University of Potsdam, Center for Sports Medicine, Recreational and High Performance Sports, Potsdam, Germany.

Received: 9 September 2012 Accepted: 18 December 2012

Published: 19 December 2012

\section{References}

1. Krag D, Weaver D, Ashikaga T, Moffat F, Klimberg VS, Shriver C, Feldman S, Kusminsky R, Gadd M, Kuhn J, Harlow S, Beitsch P: The sentinel node in breast cancer-a multicenter validation study. N Engl J Med 1998, 339(14):941-6

2. Kuehn T, Bembenek A, Decker T, Munz DL, Sautter-Bihl ML, Untch M, Wallwiener D: Consensus committee of the german society of, senology: a concept for the clinical implementation of sentinel lymph node biopsy in patients with breast carcinoma with special regard to quality assurance. Cancer 2005, 103(3):451-61.

3. Veronesi U, Galimberti V, Zurrida S, Pigatto F, Veronesi P, Robertson C, Paganelli G, Sciascia V, Viale G: Sentinel lymph node biopsy as an indicator for axillary dissection in early breast cancer. Eur J Cancer 2001, 37(4):454-8.

4. Veronesi U, Paganelli G, Galimberti V, Viale G, Zurrida S, Bedoni M, Costa A, de Cicco C, Geraghty JG, Luini A, Sacchini V, Veronesi P: Sentinel-node biopsy to avoid axillary dissection in breast cancer with clinically negative lymph-nodes. Lancet 1997, 349(9069):1864-7.

5. Giuliano AE, Haigh PI, Brennan MB, Hansen NM, Kelley MC, Ye W, Glass EC, Turner RR: Prospective observational study of sentinel lymphadenectomy without further axillary dissection in patients with sentinel nodenegative breast cancer. J Clin Oncol 2000, 18(13):2553-9.

6. Esen G, Gurses B, Yilmaz MH, Ilvan S, Ulus S, Celik V, Farahmand M, Calay OO: Gray scale and power doppler US in the preoperative evaluation of axillary metastases in breast cancer patients with no palpable lymph nodes. Eur Radiol 2005, 15(6):1215-23.

7. The NCCN Clinical Practice Guidelines in Oncology $<S U P>T M</ S U P>B R E A S T$ CANCER (V.2.2012):: @ 2010 National Comprehensive Cancer Network, Inc; [http://www.ncen.org]

8. Lucci A, McCall LM, Beitsch PD, Whitworth PW, Reintgen DS, Blumencranz PW, Leitch AM, Saha S, Hunt KK, Giuliano AE: American college of surgeons oncology, group: surgical complications associated with sentinel lymph node dissection (SLND) plus axillary lymph node dissection compared with SLND alone in the american college of surgeons oncology group trial Z0011. J Clin Oncol 2007, 25(24):3657-63.

9. Kocak Z, Overgaard J: Risk factors of arm lymphedema in breast cancer patients. Acta Oncol 2000, 39(3):389-92.

10. Giuliano AE, Hunt KK, Ballman KV, Beitsch PD, Whitworth PW, Blumencranz PW, Leitch AM, Saha S, McCall LM, Morrow M: Axillary dissection vs no axillary dissection in women with invasive breast cancer and sentinel node metastasis: a randomized clinical trial. JAMA 2011, 305(6):569-75.

11. Giuliano AE, Han SH: Local and regional control in breast cancer: role of sentinel node biopsy. Adv Surg 2011, 45:101-16.

12. Nori J, Vanzi E, Bazzocchi M, Bufalini FN, Distante V, Branconi F, Susini T: Role of axillary ultrasound examination in the selection of breast cancer patients for sentinel node biopsy. Am J Surg 2007, 193(1):16-20.

13. Alvarez S, Anorbe E, Alcorta P, Lopez F, Alonso I, Cortes J: Role of sonography in the diagnosis of axillary lymph node metastases in breast cancer: a systematic review. AJR Am J Roentgenol 2006, 186(5):1342-8.

14. March DE, Wechsler RJ, Kurtz AB, Rosenberg AL, Needleman L: CTpathologic correlation of axillary lymph nodes in breast carcinoma. J Comput Assist Tomogr 1991, 15(3):440-4.

15. Bonnema J, van Geel AN, van Ooijen B, Mali SP, Tjiam SL, Henzen-Logmans SC, Schmitz PI, Wiggers T: Ultrasound-guided aspiration biopsy for detection of nonpalpable axillary node metastases in breast cancer patients: new diagnostic method. World J Surg 1997, 21(3):270-4.

16. Lam WW, Yang WT, Chan YL, Stewart IE, Metreweli C, King W: Detection of axillary lymph node metastases in breast carcinoma by technetium-99m sestamibi breast scintigraphy, ultrasound and conventional mammography. Eur J NuCl Med 1996, 23(5):498-503.

17. Mumtaz H, Hall-Craggs MA, Davidson T, Walmsley K, Thurell W, Kissin MW, Taylor I: Staging of symptomatic primary breast cancer with MR imaging. AJR Am J Roentgenol 1997, 169(2):417-24.

18. Mussurakis S, Buckley DL, Horsman A: Prediction of axillary lymph node status in invasive breast cancer with dynamic contrast-enhanced MR imaging. Radiology 1997, 203(2):317-21

19. Uematsu T, Sano M, Homma K: In vitro high-resolution helical CT of small axillary lymph nodes in patients with breast cancer: correlation of CT and histology. AJR Am J Roentgenol 2001, 176(4):1069-74.

20. Tateishi T, Machi J, Feleppa EJ, Oishi R, Furumoto N, McCarthy L, Yanagihara E, Uchida S, Noritomi T, Shirouzu K: In vitro B-mode ultrasonographic criteria for diagnosing axillary lymph node metastasis of breast cancer. J Ultrasound Med 1999, 18(5):349-56.

21. Hahn M, Roessner L, Krainick-Strobel U, Gruber IV, Kramer B, Gall C, Siegmann KC, Wallwiener D, Kagan KO: [Sonographic criteria for the differentiation of benign and malignant breast lesions using real-time spatial compound imaging in combination with XRES adaptive image processing]. Ultraschall in der Medizin 2012, 33(3):270-4.

22. Wojcinski S, Farrokh A, Weber S, Thomas A, Fischer T, Slowinski T, Schmidt W, Degenhardt F: Multicenter study of ultrasound real-time tissue elastography in 779 cases for the assessment of breast lesions: improved diagnostic performance by combining the BI-RADS(R)-US classification system with sonoelastography. Ultraschall in der Medizin 2010, 31(5):484-91.

23. Schulz-Wendtland R, Bock K, Aichinger U, de Waal J, Bader W, Albert US, Duda VF: [Ultrasound examination of the breast with $7.5 \mathrm{MHz}$ and $13 \mathrm{MHz}$-transducers: scope for improving diagnostic accuracy in complementary breast diagnostics?]. Ultraschall in der Medizin 2005, 26(3):209-15.

24. Farrokh A, Wojcinski S, Degenhardt F: [Diagnostic value of strain ratio measurement in the differentiation of malignant and benign breast lesions]. Ultraschall in der Medizin 2011, 32(4):400-5.

25. Thomas A, Degenhardt F, Farrokh A, Wojcinski S, Slowinski T, Fischer T: Significant differentiation of focal breast lesions: calculation of strain ratio in breast sonoelastography. Acad Radiol 2010, 17(5):558-63. 
26. Sadigh G, Carlos RC, Neal CH, Dwamena BA: Ultrasonographic differentiation of malignant from benign breast lesions: a meta-analytic comparison of elasticity and BIRADS scoring. Breast Cancer Res Treat 2012, 133(1):23-35.

27. Lyshchik A, Higashi T, Asato R, Tanaka S, Ito J, Hiraoka M, Insana MF, Brill AB, Saga T, Togashi K: Cervical lymph node metastases: diagnosis at sonoelastography-initial experience. Radiology 2007, 243(1):258-67.

28. Alam F, Naito K, Horiguchi J, Fukuda H, Tachikake T, Ito K: Accuracy of sonographic elastography in the differential diagnosis of enlarged cervical lymph nodes: comparison with conventional B-mode sonography. AJR Am J Roentgenol 2008, 191(2):604-10.

29. Bhatia KS, Cho CC, Yuen YH, Rasalkar DD, King AD, Ahuja AT: Real-time qualitative ultrasound elastography of cervical lymph nodes in routine clinical practice: interobserver agreement and correlation with malignancy. Ultrasound Med Biol 2010, 36(12):1990-7.

30. Tan R, Xiao Y, He Q: Ultrasound elastography: its potential role in assessment of cervical lymphadenopathy. Acad Radiol 2010, 17(7):849-55.

31. Janssen J, Dietrich CF, Will U, Greiner L: Endosonographic elastography in the diagnosis of mediastinal lymph nodes. Endoscopy 2007, 39(11):952-7.

32. Giovannini M, Hookey LC, Bories E, Pesenti C, Monges G, Delpero JR: Endoscopic ultrasound elastography: the first step towards virtual biopsy? preliminary results in 49 patients. Endoscopy 2006, 38(4):344-8

33. Giovannini $M$, Thomas B, Erwan B, Christian P, Fabrice C, Benjamin E, Genevieve M, Paolo A, Pierre D, Robert Y, Walter S, Hanz S, Carl S, Christoph $D$, Pierre E, Jean-Luc VL, Jacques D, Peter V, Andrian S: Endoscopic ultrasound elastography for evaluation of lymph nodes and pancreatic masses: a multicenter study. World J Gastroenterol 2009, 15(13):1587-93.

34. Aoyagi S, Izumi K, Hata H, Kawasaki H, Shimizu H: Usefulness of real-time tissue elastography for detecting lymph-node metastases in squamous cell carcinoma. Clin Exp Dermatol 2009, 34(8):e744-7.

35. Choi JJ, Kang BJ, Kim SH, Lee JH, Jeong SH, Yim HW, Song BJ, Jung SS: Role of sonographic elastography in the differential diagnosis of axillary lymph nodes in breast cancer. J Ultrasound Med 2011, 30(4):429-36.

36. Taylor K, OrKeeffe S, Britton PD, Wallis MG, Treece GM, Housden J, Parashar D, Bond S, Sinnatamby R: Ultrasound elastography as an adjuvant to conventional ultrasound in the preoperative assessment of axillary lymph nodes in suspected breast cancer: a pilot study. Clin Radiol 2011, 66(11):1064-71.

37. DEGUM (Deutsche Gesellschaft für Ultraschall in der Medizin). Mehrstufenkonzept Mammasonographie; [http://www.degum.de/ Mehrstufenkonzept_Mammasonogra.634.0.html].

38. Frey $H$, Ignee A, Dietrich CF: Elastographie, ein neues bildgebendes verfahren. Endosk heute 2006, 19:117-120. 117

39. Stavros AT: Breast ultrasound. 1st edition. Philadelphia, PA: Lippincott Williams \& Wilkins; 2004.

40. Ueno E, Tohno E, Soeda S, Asaoka Y, Itoh K, Bamber JC, Blaszczyk M, Davey J, McKinna JA: Dynamic tests in real-time breast echography. Ultrasound Med Biol 1988, 14(Suppl 1):53-7.

41. Evans A, Whelehan P, Thomson K, Brauer K, Jordan L, Purdie C, McLean D, Baker $L$, Vinnicombe $S$, Thompson A: Differentiating benign from malignant solid breast masses: value of shear wave elastography according to lesion stiffness combined with greyscale ultrasound according to BI-RADS classification. Br J Cancer 2012, 107(2):224-9.

42. Friedrich-Rust M, Nierhoff J, Lupsor M, Sporea I, Fierbinteanu-Braticevici C, Strobel D, Takahashi H, Yoneda M, Suda T, Zeuzem S, Herrmann E: Performance of acoustic radiation force impulse imaging for the staging of liver fibrosis: a pooled meta-analysis. J Viral Hepat 2012, 19(2):e212-9.

43. Newcombe RG: Interval estimation for the difference between independent proportions: comparison of eleven methods. Stat Med 1998, 17(8):873-90.

44. Tan LG, Tan $Y Y$, Heng D, Chan MY: Predictors of axillary lymph node metastases in women with early breast cancer in singapore. Singapore Med J 2005, 46(12):693-7.

45. Chan GS, Ho GH, Yeo AW, Wong CY: Correlation between breast tumour size and level of axillary lymph node involvement. Asian J Surg 2005, 28(2):97-9.

46. UICC: TNM Classification of Malignant Tumours. Hoboken, NJ: John Wiley \& Sons; 2002.

47. Chua B, Ung O, Taylor R, Boyages J: Is there a role for axillary dissection for patients with operable breast cancer in this era of conservatism? ANZ J Surg 2002, 72(11):786-792.
48. Yip CH, Taib NA, Tan GH, Ng KL, Yoong BK, Choo WY: Predictors of axillary lymph node metastases in breast cancer: is there a role for minimal axillary surgery? World J Surg 2009, 33(1):54-57.

49. Wojcinski S, Cassel M, Farrokh A, Soliman AA, Hille U, Schmidt W, Degenhardt F, Hillemanns P: Variations in the elasticity of breast tissue during the menstrual cycle determined by real-time sonoelastography. J Ultrasound Med 2012, 31(1):63-72.

50. Mendelson EB, Baum JK, Berg WA, Merritt CR, Rubin E: BI-RADS: Ultrasound. In In In Breast Imaging Reporting and Data System: ACR BI-RADS - Breast Imaging Atlas. Edited by DıOrsi CJ, Mendelson EB, Ikeda DM. Reston, VA: American College of Radiology; 2002.

51. Itoh A, Ueno E, Tohno E, Kamma H, Takahashi H, Shiina T, Yamakawa M, Matsumura T: Breast disease: clinical application of US elastography for diagnosis. Radiology 2006, 239(2):341-50.

52. Saftoiu A, Vilmann P, Hassan H, Gorunescu F: Analysis of endoscopic ultrasound elastography used for characterisation and differentiation of benign and malignant lymph nodes. Ultraschall in der Medizin 2006, 27(6):535-42.

doi:10.1186/1471-2342-12-35

Cite this article as: Wojcinski et al:: Real-time ultrasound elastography in 180 axillary lymph nodes: elasticity distribution in healthy lymph nodes and prediction of breast cancer metastases. BMC Medical Imaging 2012 12:35.

\section{Submit your next manuscript to BioMed Central and take full advantage of:}

- Convenient online submission

- Thorough peer review

- No space constraints or color figure charges

- Immediate publication on acceptance

- Inclusion in PubMed, CAS, Scopus and Google Scholar

- Research which is freely available for redistribution

Submit your manuscript at www.biomedcentral.com/submit
C) Biomed Central 